\title{
Correction to: Dynamic serum biomarkers to predict the efficacy of PD-1 in patients with nasopharyngeal carcinoma
}

\author{
Ao Zhang ${ }^{1}$, Guanqing Zhong ${ }^{1}$, Luocan Wang ${ }^{1}$, Rongzeng Cai ${ }^{1}$, Runkun Han ${ }^{1}$, Caixia Xu' ${ }^{2}$, Shulin Chen ${ }^{12^{*}}$, \\ Peng Sun ${ }^{3^{*}}$ and Hao Chen ${ }^{1 *}$ (i)
}

\section{Correction to: Cancer Cell Int (2021) 21:518 https://doi.org/10.1186/s12935-021-02217-y}

In this article [1], the affiliation details for Shulin Chen and Peng Sun were incorrectly given as " 1 " and " 2,3 " but should have been " 1,2 " and " 3 ", respectively.

The affiliations are corrected with this correction. The correct unit labeling should be as follows:

Ao Zhang ${ }^{1}$, Guanqing Zhong ${ }^{1}$, Luocan Wang ${ }^{1}$, Rongzeng Cai ${ }^{1}$, Runkun $\mathrm{Han}^{1}$, Caixia Xu${ }^{2}$, Shulin Chen ${ }^{1,2^{*}}$, Peng Sun $^{3^{*}}$ and Hao Chen ${ }^{1^{*}}$

\section{Author details}

'Department of Clinical Laboratory, State Key Laboratory of Oncology in South China, Collaborative Innovation Center for Cancer Medicine, Guangdong Key Laboratory of Nasopharyngeal Carcinoma Diagnosis and Therapy, Sun Yat-Sen University Cancer Center, Guangzhou 510060, People's Republic of China. ${ }^{2}$ Research Center for Translational Medicine, The First Affliated Hospital, Sun Yat-Sen University, 58 Zhongshan Road 2, Guangzhou 510080, Guangdong, People's Republic of China. ${ }^{3}$ Department of Medical Oncology,
State Key Laboratory of Oncology in South China, Collaborative Innovation Center for Cancer Medicine, Guangdong Key Laboratory of Nasopharyngeal Carcinoma Diagnosis and Therapy, Sun Yat-Sen University Cancer Center, Guangzhou 510060, People's Republic of China.

Accepted: 25 November 2021

Published online: 02 December 2021

\section{Reference}

1. Zhang A, Zhong G, Wang L, Cai R, Han R, Xu C, Chen S, Sun P, Chen H. Dynamic serum biomarkers to predict the efficacy of PD-1 in patients with nasopharyngeal carcinoma. Cancer Cell Int. 2021;21:518. https://doi. org/10.1186/s12935-021-02217-y.

\section{Publisher's Note}

Springer Nature remains neutral with regard to jurisdictional claims in published maps and institutional affiliations.

${ }^{1}$ Department of Clinical Laboratory, State Key Laboratory of Oncology in South China, Collaborative Innovation Center for Cancer Medicine, Guangdong Key Laboratory of Nasopharyngeal Carcinoma Diagnosis and Therapy, Sun Yat-Sen University Cancer Center, Guangzhou 510060, People's Republic of China

${ }^{3}$ Department of Medical Oncology, State Key Laboratory of Oncology in South China, Collaborative Innovation Center for Cancer Medicine, Guangdong Key Laboratory of Nasopharyngeal Carcinoma Diagnosis and Therapy, Sun Yat-Sen University Cancer Center, Guangzhou 510060, People's Republic of China

Full list of author information is available at the end of the article original author(s) and the source, provide a link to the Creative Commons licence, and indicate if changes were made. The images or other third party material in this article are included in the article's Creative Commons licence, unless indicated otherwise in a credit line to the material. If material is not included in the article's Creative Commons licence and your intended use is not permitted by statutory regulation or exceeds the permitted use, you will need to obtain permission directly from the copyright holder. To view a copy of this licence, visit http://creativecommons.org/licenses/by/4.0/. The Creative Commons Public Domain Dedication waiver (http://creativecommons.org/publicdomain/zero/1.0/) applies to the data made available in this article, unless otherwise stated in a credit line to the data. 